\title{
Normative values of muscular and cardiorespiratory fitness and their relationship with anthropometric variables in Colombian adolescents. Multicentre study
}

\author{
Valores normativos de aptitud muscular y cardiorrespiratoria y su relación con \\ variables antropométricas en adolescentes colombianos. Estudio multicéntrico \\ *Brayan Esneider Patiño Palma, **Carlos Alberto Ramos Parrací, ***Pedro Antonio Calero Saa \\ *Ministerio Colombiano del Deporte, Centro de Ciencias del Deporte y Universidad Santiago de Cali (Colombia), **Universidad Del \\ Tolima (Colombia), ***Universidad Santiago de Cali (Colombia)
}

\begin{abstract}
Objectives: The purposes of this research were: 1. To establish reference values for cardiorespiratory fitness and muscular fitness. 2. To establish the relationship between anthropometric characteristics and physical fitness parameters. Materials and Methods: Cross-sectional, multicentre, analytical study; students aged between 12 and 18 years from 10 Colombian cities were evaluated. The sample was 3455 students with a reliability of $95 \%$, a statistical power of $84 \%$, and an expected correlation of 0.30 . Anthropometric variables, General Strength Index (GSI), and Cardiopulmonary Capacity were taken into account. A two-way analysis of variance (two-way ANOVA) was performed with Bonferroni post hoc adjustments. A Box-Cox Cole and Green (BCCG) lest squares method (LMS) distribution was performed. Results: A higher performance was found on males in all tests performed, and a higher average body mass index (BMI), waist-height index, and fat percentage on the females. Weak to moderate negative correlations were identified between muscular and cardiopulmonary fitness and anthropometric variables. Additionally, significant differences were identified between GSI with waist circumference and fat percentage. Conclusion: Cardiorespiratory fitness assessment and GSI are tools to be considered as a complement to the evaluation of academic programs with school health prevention objectives.
\end{abstract}

KeyWords: ReferenceValues, Cardiorespiratory Fitness, Muscle Strength, Adolescent.

Resumen: Objetivos: Los objetivos de esta investigación fueron: 1. Establecer valores de referencia para la aptitud cardiorrespiratoria y la aptitud muscular. 2. Establecer la relación entre características antropométricas y parámetros de aptitud física. Materiales y Métodos: Estudio analítico, transversal, multicéntrico; Se evaluó a estudiantes de entre 12 y 18 años de 10 ciudades colombianas. La muestra fue de 3455 estudiantes con una confiabilidad del $95 \%$, un poder estadístico del $84 \%$ y una correlación esperada de 0.30 . Se tomaron en cuenta variables antropométricas, Índice de Fuerza General (GSI) y Capacidad Cardiopulmonar. Se realizó un análisis de varianza bidireccional (ANOVA bidireccional) con ajustes post hoc de Bonferroni. Se realizó el cálculo de los percentiles normalizados a partir del método de mínimos cuadrados (LMS) de Box-Cox Cole y Green (BCCG). Resultados: Se encontró un mayor rendimiento en los hombres en todas las pruebas realizadas, sin embargo, se evidencio un índice de masa corporal (IMC) promedio, índice de cintura y porcentaje de grasa más altos en las mujeres. Se identificaron correlaciones negativas débiles a moderadas entre la aptitud muscular y cardiopulmonar y las variables antropométricas. Además, se identificaron diferencias significativas entre GSI con la circunferencia de cintura y el porcentaje de grasa. Conclusión: La evaluación de la aptitud cardiorrespiratoria y el GSI son herramientas a considerar como un complemento a la evaluación de los programas académicos con objetivos de prevención en salud escolar.

Palabras clave:Valores de referencia, Resistencia Física, Fuerza Muscular, Adolescente.

\section{Introduction}

Physical fitness is an indicator and predictor of adequate health. This consists of body composition, cardiorespiratory fitness, muscular fitness, and flexibility (Kidokoro et al., 2020). Physical Fitness is considered as a measure that is integrated into most of the bodily functions that are involved in the performance of the daily physical activity or physical exercise and, in addition, it is considered as an important indicator of health in childhood. (Mayorga et al., 2012).

Fecha recepción: 14-04-21. Fecha de aceptación: 07-09-21

Brayan Esneider Patiño Palma

brpatinop@mindeporte.gov.co
According to previous studies, both cardiorespiratory fitness and muscular fitness as measured by grip strength are associated with cardiovascular mortality, premature death (Kodama et al., 2009; Leong et al., 2015; F. B. Ortega et al., 2012; Silventoinen et al., 2009) and functional impairment (El gohary et al., 2019). Additionally, muscular strength is negatively associated with overall adiposity, and adequate body composition is associated with a healthy future cardiovascular profile and a decreased risk of death(J. R. Ruiz et al., 2009).

The study carried by Syddall (Syddall et al., 2003) determined that grip strength significantly correlates with personal independence, allowing for greater functionality over a longer period of time, which in 
turn becomes a protective characteristic in young adults. Grip strength assessment is a practical means of stratifying cardiovascular death risk and assessing general muscle function and deficiencies (Kara et al., 2021; Kim et al., 2021). Therefore, it becomes a very useful strategy to monitor the health status of an individual.

Regarding body composition, assessed employing the Body Mass Index (BMI), is associated with the risk of cardiovascular disease (Álvarez Caro et al., 2011; Zorrilla-López et al., 2020) and quality of life (LimaSerrano et al., 2018). These variables are considered important for identifying potentially preventable health risks for metabolic and cardiovascular diseases, making physical activity an appropriate strategy for reducing health risks (Zaccagni et al., 2014).

As mentioned above, health-related fitness is defined as a dynamic state that allows the individual to perform daily activities and cope with unforeseen situations without fatigue (Gómez-Campos et al., 2020); It is important to mention that the constant improvement of physical fitness related to health (cardiorespiratory fitness, muscular fitness, and body composition) is necessary to produce neurobiological adaptations that are expressed in beneficial adaptations such as psychosocial stressors through axis adjustments hypothalamic-pituitary-adrenocortical and the sympathoadrenal medullary system that lead to improved mental health (Janssen et al., 2020).

In this context, students face academic years spanning high school and university, which become periods where they make lifestyle choices, where unhealthy behavior influenced by dietary imbalance and increased hypokinetic activities increases due to academic stress and experiences of freedom (Kidokoro et al., 2020). According to data collected from the university population in Colombia in 2012, the probability of cerebrovascular disease occurring at an early age is determined by the synergistic effect of being exposed to cardiovascular risk factors at some point in life (Carvajal et al., 2012).

Academic dynamics generate the possibility of changing interventions according to the individual, the environment, and their background. For this reason, identifying baseline values makes it possible to characterize behaviors and design clear interventions for health promotion and prevention in the academic population.

For this reason, this work consists of two intentions: 1. To establish reference values for cardiorespiratory fitness and muscular fitness. 2. To establish the relationship between anthropometric characteristics and physical fitness parameters.

\section{Materials and methods}

\section{Study design and sample}

A cross-sectional descriptive study with a quantitative approach, the population consisted of school children between 12 and 18 years old from public and private schools in ten Colombian cities (Manizales, Armenia, Pasto, Popayan, Valledupar, Tuluá, Riosucio, Villamaría, Chinchiná, and Dosquebradas). To calculate the sample, reliability of $95 \%$, the statistical power of $84 \%$, and an expected correlation of 0.30 were taken into account, thus establishing a representative sample size of 345 students from each city, obtaining a total of 3455 students who met the inclusion criteria. The selection of the sample was done in a stratified way in public and private schools as mentioned above. This project was approved by the Bioethics Committee of the Universidad Autónoma de Manizales under act 062 of February 15, 2017, besides, the assessments were made regarding the provisions of the Declaration of Helsinki and resolution 008430 of the Ministry of Health and Social Protection of Colombia. In addition, each participant from this study read and signed an informed consent form.

\section{Body composition measurement}

All body dimension measurements were performed with the subjects barefoot and in comfortable clothing following the protocol established by the International Society for the Advancement of Kinanthropometry (ISAK). Weight was measured with a TANITA $\AA$ floor scale model BF (Arlington Heights, IL 60005, USA) with a maximum capacity of $200 \mathrm{~kg}$ and a minimum capacity of $100 \mathrm{~g}$. Height was measured with a SECA $\AA$ portable stadiometer model 206 (Hamburg, Germany,) range $0-220 \mathrm{~cm}$ and $1 \mathrm{~mm}$ accuracy. With these variables, the body mass index (BMI) in $\mathrm{kg} / \mathrm{m}^{2}$ was calculated.

The waist circumference (WC) was taken according to the anatomical references described by the WHO (World Health Organization (WHO), 1995), and from the direct measurements, the waist-to-height ratio (WHR) was calculated.

The fat percentage was estimated from the equations proposed by Slaughter (Slaughter et al., 1988) which uses the tricipital and subscapular folds; these folds were measured with a Slim Guide adipometer, calibrated every 100 measurements. 


\section{General Strength Index}

The general strength index (GSI) was determined from the manual grip test and the long jump test. The maximum manual grip strength was measured using a Takei $\mathrm{R}$ digital dynamometer with an adjustable handle, modelTKK-5101, which is accurate to $100 \mathrm{~g}$, previously shown to have high reliability in young men $(r=0.88$ 0.98) (Francisco Ortega et al., 2012). Two attempts were made with each hand alternately in a standardized position (standing, arms parallel to the body without any contact) with a rest time of 60 seconds between attempts. The device handle was adjusted to accommodate participants' hand size such that the index finger of each hand was at $90^{\circ}$ flexion between the proximal and middle phalangeal joint. The highest value obtained between the different attempts is considered as the Handgrip strength (HGS) and was expressed in kilograms. According to the methodology applied by Palacio-Agüero et al (2020) and Yi et al (2018) the relative grip strength (RHGS) was calculated by dividing the maximum HGS by the BMI.

The standing long jump test, as a test to determine lower body explosive strength, was performed from the standard starting position (standing behind a reference line with feel shoulder-wide apart), the adolescent jumped as far forward as possible, landing with feet together. The evaluators involved in the fieldwork were advised to perform this test on a hard, non-slip surface. The test was performed twice and the longest distance achieved was recorded in centimeters.

With the results from these tests, the GSI was calculated from the Z-typing, with the formula $\mathrm{Z}=$ (mean value / standard deviation). The average of the 2 transformed tests (z-score) was used to establish a single variable called GSI. Subsequently, the GSI was recoded into quartiles $(\mathrm{Q})$, with $\mathrm{Q} 4$ being the position with the highest value in muscle performance.

\section{0 m Shuttle Run Test (Leger Test)}

For the evaluation of cardiorespiratory capacity, the 20-M Shuttle-Run Test was carried out, a validated test for the evaluation of adults, adolescents, and children as established by Magee et al. (2021) and Matsuzaka et al. (2004).

Participants were asked to run between two lines 20 meters apart while keeping pace with the audio signals played from prerecorded CDs. The initial speed was $8.5 \mathrm{~km} / \mathrm{h}$, increasing $0.5 \mathrm{~km} / \mathrm{h}$ every minute (1-minute equals one stage). Participants were instructed to run in a straight line, turn after completing $20 \mathrm{~m}$ and keep pace according to the audio cues. The test ended when the participant stopped due to fatigue or could not reach the goal at the same time as the audio signal on two consecutive occasions. Each participant took the test once and the last complete stage performed by the participant was recorded.

\section{Statistical analysis}

Data analysis was carried out using $25^{\text {th }}$ version SPSS software with the respective data cleaning and debugging. The normal distribution of the variables was verified using the Kolmogorov-Smirnov test.

Partial correlations adjusted by sex and age were performed to examine bivariate correlations of muscular and cardiorespiratory fitness with body dimension measures. Two-way analysis of variance (two-way ANOVA) was used to determine differences between sex and age and to identify differences in body dimension measures between muscular fitness quartiles and sex; this analysis was performed with Bonferroni's post hoc adjustments.

Finally, we proceeded to construct the cross-sectional percentiles for each of the tests used in this study. The Box-Cox Cole and Green (BCCG) distribution of the method known as least squares or LMS (Cole \& Green, 1992) was used. This model was implemented through the library of generalized additive models by location, scale, and shape (GAMLSS), given that it improves in efficiency and precision compared to the classical techniques of linear least squares(Stasinopoulos \& Rigby, 2007). All of the above was carried out using the statistical software R version 3.4.0. (Wilson \& Norden, 2015)

The LMS method was run for both sexes by predicting and transforming the original data to normalized data or also known as Z score data, to have the normal behavior of the study variables and to establish the reference values for this population. Statistical significance was set at a value $\mathrm{p}<0,05$.

\section{Results}

The anthropometric characteristics and physical fitness parameters of the study sample are shown in table 1 . In summary, male adolescents showed better performance in each of the tests executed, as well as greater weight, height, and waist circumference compared to the female population. However, it should be noted that girl adolescents had higher average values for BMI, waist-to-heigh ratio, and fat percentage. 
Table 1.

\begin{tabular}{|c|c|c|c|c|}
\hline & Male (1733) & Female (1722) & Total & $P$ value \\
\hline Age (years) & $15 \pm 1,99$ & $14,96 \pm 1,98$ & $14,98 \pm 1,98$ & ,548 \\
\hline Weight $(\mathrm{kg})$ & $55,68 \pm 11,96$ & $52,89 \pm 9,78$ & $54,26 \pm 11,02$ & ,000 \\
\hline Height $(\mathrm{cm})$ & $164,27 \pm 10,45$ & $158,14 \pm 7,8$ & $161,21 \pm 9,72$ & ,000 \\
\hline BMI $(\mathrm{kg} / \mathrm{m} 2)$ & $20,43 \pm 3,12$ & $21,07 \pm 3,27$ & $20,75 \pm 3,21$ & ,000 \\
\hline Under weight & 27 & 21,3 & 24,2 & \\
\hline Normal weight & 63,7 & 64,9 & 64.9 & \\
\hline Weight Status Overweight & 7,2 & 10,1 & 8,6 & \\
\hline Obesity I & 0,9 & 1,1 & 1 & \\
\hline Obesity II & 0,1 & 0,1 & 0,1 & \\
\hline Obesity III & 1,2 & 1,2 & 1,2 & \\
\hline Waist Perimeter & $69,81 \pm 7,77$ & $68,59 \pm 7,98$ & $69,20 \pm 7,89$ & ,000 \\
\hline Waist-to-height ratio & $0,42 \pm 0,048$ & $0,43 \pm 0,052$ & $0,43 \pm 0,05$ & ,000 \\
\hline Average of fat & $23,80 \pm 8,32$ & $28,03 \pm 11,45$ & $25,92 \pm 10,22$ & ,000 \\
\hline Handgrip strength (kg) & $33,01 \pm 10,38$ & $25,39 \pm 7,07$ & $29,21 \pm 9,67$ & ,000 \\
\hline Relative hand grip strength & $0,59 \pm 0,15$ & $0,48 \pm 0,12$ & $0,54 \pm 0,14$ & ,000 \\
\hline Long jump to feet together $(\mathrm{cm})$ & $172,36 \pm 36,02$ & $136,49 \pm 29,75$ & $154,48 \pm 37,59$ & ,000 \\
\hline $20 \mathrm{~m}$ Shuttle Run Test (level) & $5,95 \pm 2,55$ & $4,11 \pm 1,96$ & $5,03 \pm 2,45$ & ,000 \\
\hline 20 m Shuttle Run Test (m) & $830,6 \pm 466,8$ & $507,2 \pm 333$ & $669 \pm 436$ & ,000 \\
\hline
\end{tabular}

Table 2 shows the partial correlations of muscular and cardiorespiratory fitness with the variables of body dimension. Negative correlations were observed with a weak to moderate clinical significance, finding that the higher the body mass index, the percentage of fat and/or the waist-to-height ratio, the lower the performance in relative manual force, the absolute manual force, the general index of force and the lower the performance in the $20 \mathrm{~m}$ Shuttle Run Test.

Table 2.

$\underline{\text { Partial correlations of muscular and cardiorespiratory fitness with the body dimension variables }}$ Rethic and cardiorespiratory fitness with the body dimension variables

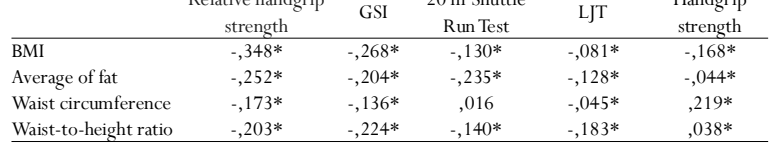

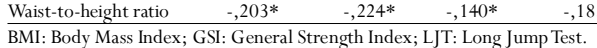

Pearson correlation $* \mathrm{P}<, 001$. $\mathrm{P}$ values are from a bilateral test (two-tailed).

Figure 1 shows the behavior between muscular fitness and body dimension variables taking into account sex, finding statistically significant differences between the groups. The post hoc analysis revealed that participants with low muscular fitness had higher values of waist-to-height ratio and BMI, but the behavior between sexes was similar (Figure 1A and 1B).
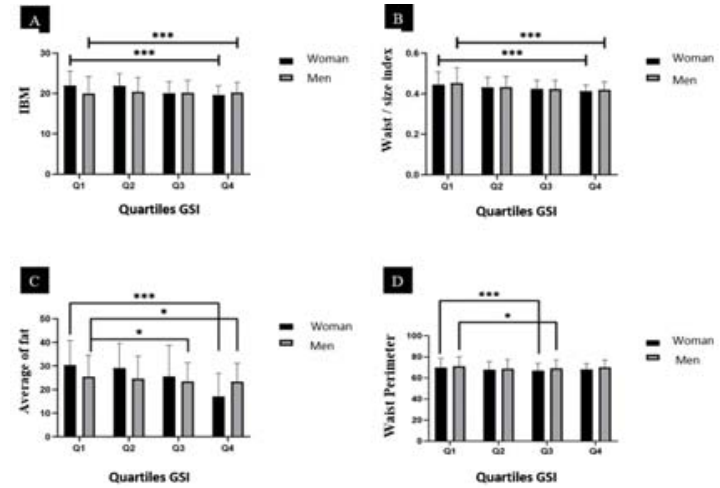

Figure 1. The behavior between muscular fitness and body dimension variables according to sex Analyses among the variables of interest show that an increase in strength (GSI) values are related to lower body dimension indicators (GSI: General Strength Index; BMI: Body Mass Index; WC: Waist Circumference; WHR: waist-to-height Ratio; \%BF: Body fat percentage). A). GSI vs. BMI; B). GSI vs. WHR; C). GSI v. $\%$ BF; D). GSI vs.WC. Significant differences for the low GSI group (Q1) are expressed. *Differences by sex with ANOVA test. $*_{p}<, 05 * * p<, 01 * * * p<, 001$
Table 3.

Standardized reference values for the male gender

\begin{tabular}{|c|c|c|c|c|c|c|c|}
\hline \multicolumn{8}{|l|}{ Long jump test } \\
\hline Z score/Age & -3 & -2 & -1 & 0 & 1 & 2 & 3 \\
\hline 12 & 60 & 90 & 119 & 149 & 177 & 203 & 228 \\
\hline 13 & 80 & 110 & 128 & 159 & 187 & 213 & 239 \\
\hline 14 & 90 & 115 & 138 & 169 & 199 & 226 & 253 \\
\hline 15 & 100 & 119 & 146 & 179 & 210 & 239 & 268 \\
\hline 16 & 102 & 120 & 147 & 185 & 220 & 252 & 283 \\
\hline 17 & 107 & 127 & 151 & 188 & 223 & 255 & 287 \\
\hline 18 & 114 & 135 & 149 & 186 & 221 & 253 & 284 \\
\hline \multicolumn{8}{|c|}{$\begin{array}{l}\text { Handgrip strength }(\mathrm{kg}) \\
\end{array}$} \\
\hline 12 & 8,5 & 12,2 & 16,5 & 21,4 & 27,6 & 35,9 & 48,5 \\
\hline 13 & 10,6 & 15,1 & 20,1 & 26,0 & 33,3 & 43,1 & 57,8 \\
\hline 14 & 12,5 & 17,6 & 23,4 & 30,0 & 38,2 & 49,2 & 65,5 \\
\hline 15 & 14,2 & 19,9 & 26,3 & 33,6 & 42,6 & 54,7 & 72,6 \\
\hline 16 & 15,3 & 21,6 & 28,5 & 36,6 & 46,5 & 59,8 & 79,6 \\
\hline 17 & 16,2 & 22,8 & 30,0 & 38,4 & 48,8 & 62,7 & 83,3 \\
\hline 18 & 16,7 & 23,4 & 30,6 & 39,0 & 49,2 & 62,9 & 93,0 \\
\hline \multicolumn{8}{|c|}{ Relative hand grip strength } \\
\hline 12 & 0,22 & 0,30 & 0,39 & 0,51 & 0,64 & 0,80 & 0,98 \\
\hline 13 & 0,23 & 0,31 & 0,42 & 0,54 & 0,69 & 0,87 & 1,08 \\
\hline 14 & 0,25 & 0,34 & 0,44 & 0,57 & 0,72 & 0,90 & 1,11 \\
\hline 15 & 0,27 & 0,36 & 0,46 & 0,59 & 0,75 & 0,93 & 1,15 \\
\hline 16 & 0,28 & 0,37 & 0,48 & 0,62 & 0,78 & 0,97 & 1,19 \\
\hline 17 & 0,28 & 0,37 & 0,49 & 0,63 & 0,79 & 0,99 & 1,22 \\
\hline 18 & 0,28 & 0,37 & 0,49 & 0,63 & 0,79 & 0,99 & 1,22 \\
\hline \multicolumn{8}{|c|}{$20 \mathrm{~m}$ Shuttle Run Test (level) } \\
\hline 12 & 1,6 & 2,5 & 3,8 & 4,6 & 6,9 & 9,6 & 12,8 \\
\hline 13 & 1,7 & 2,7 & 4,2 & 5,2 & 7,7 & 10,7 & 14,3 \\
\hline 14 & 1,7 & 2,8 & 4,4 & 5,4 & 8,0 & 11,1 & 14,8 \\
\hline 15 & 1,8 & 2,9 & 4,6 & 5,8 & 8,5 & 11,8 & 15,7 \\
\hline 16 & 1,9 & 3,0 & 4,8 & 6,1 & 9,0 & 12,4 & 16,3 \\
\hline 17 & 1,8 & 3,1 & 4,9 & 6,3 & 9,4 & 13,1 & 17,4 \\
\hline 18 & 1,7 & 3,9 & 5,0 & 6,3 & 9,4 & 13,3 & 17,9 \\
\hline
\end{tabular}

Percentile values were used through the LMS method with the BCCG method.

In contrast, statistically significant differences were found between GSI with waist circumference and fat percentage, however, the post hoc analysis showed that for waist circumference the difference found was between quartile 1 and quartile 3 (Figure 1C); being similar for both, males and females. On the other hand, regarding the fat percentage, the differences found in the females were between quartile 1 and the other quartiles, but on the contrary, for the males, the differences observed were only between quartile 1 and

Table 4

Standardized reference values for the female gender

\begin{tabular}{|c|c|c|c|c|c|c|c|}
\hline \multicolumn{8}{|c|}{ Long jump test } \\
\hline Z score/age & -3 & -2 & -1 & 0 & 1 & 2 & 3 \\
\hline 12 & 55 & 75 & 100 & 125 & 153 & 182 & 212 \\
\hline 13 & 64 & 90 & 107 & 131 & 157 & 185 & 213 \\
\hline 14 & 80 & 95 & 111 & 137 & 165 & 194 & 224 \\
\hline 15 & 92 & 100 & 112 & 140 & 169 & 201 & 234 \\
\hline 16 & 92 & 105 & 111 & 140 & 171 & 203 & 237 \\
\hline 17 & 99 & 108 & 120 & 140 & 173 & 208 & 245 \\
\hline 18 & 106 & 115 & 123 & 136 & 172 & 210 & 250 \\
\hline \multicolumn{8}{|c|}{ Handgrip strength $(\mathrm{kg})$} \\
\hline 12 & 9,3 & 13,0 & 16,5 & 20,3 & 25,5 & 34,5 & 38,4 \\
\hline 13 & 10,7 & 14,6 & 18,4 & 22,5 & 27,9 & 37,2 & 41,0 \\
\hline 14 & 11,5 & 15,7 & 19,7 & 24,0 & 29,7 & 39,4 & 44,0 \\
\hline 15 & 11,7 & 16,2 & 20,5 & 25,2 & 31,5 & 42,4 & 45,7 \\
\hline 16 & 12,0 & 16,8 & 21,3 & 26,3 & 32,9 & 44,6 & 50,4 \\
\hline 17 & 12,4 & 17,2 & 22,1 & 26,6 & 34,1 & 47,8 & 56,7 \\
\hline 18 & 12,7 & 17,5 & 22,8 & 27,9 & 35,6 & 48,0 & 60,4 \\
\hline \multicolumn{8}{|c|}{ Relative hand grip strength } \\
\hline 12 & 0,23 & 0,29 & 0,36 & 0,46 & 0,59 & 0,75 & 0,95 \\
\hline 13 & 0,22 & 0,29 & 0,36 & 0,46 & 0,59 & 0,76 & 0,97 \\
\hline 14 & 0,23 & 0,29 & 0,36 & 0,47 & 0,59 & 0,76 & 0,98 \\
\hline 15 & 0,24 & 0,30 & 0,37 & 0,47 & 0,60 & 0,76 & 0,96 \\
\hline 16 & 0,25 & 0,31 & 0,39 & 0,49 & 0,61 & 0,77 & 0,98 \\
\hline 17 & 0,23 & 0,30 & 0,38 & 0,49 & 0,63 & 0,81 & 1,04 \\
\hline 18 & 0,21 & 0,27 & 0,35 & 0,46 & 0,60 & 0,79 & 1,04 \\
\hline \multicolumn{8}{|c|}{$20 \mathrm{~m}$ Shuttle Run Test (level) } \\
\hline 12,0 & 1,0 & 1,2 & 2,1 & 3,4 & 5,4 & 8,4 & 12,6 \\
\hline 13,0 & 1,2 & 1,3 & 2,2 & 3,6 & 5,7 & 8,7 & 12,9 \\
\hline 14,0 & 1,2 & 1,3 & 2,2 & 3,6 & 5,7 & 8,6 & 12,7 \\
\hline 15,0 & 1,2 & 1,3 & 2,2 & 3,7 & 5,8 & 8,9 & 13,4 \\
\hline 16,0 & 1,2 & 1,3 & 2,3 & 3,9 & 6,3 & 9,8 & 14,8 \\
\hline 17,0 & 1,3 & 1,4 & 2,4 & 4,0 & 6,5 & 10,1 & 15,4 \\
\hline 18,0 & 1,3 & 1,4 & 2,4 & 3,9 & 6,2 & 9,6 & 14,4 \\
\hline
\end{tabular}


quartile 3 and 4 (Figure 1D).

Tables 3 and 4 show the reference values for the prehensile strength, the long jump, and the $20 \mathrm{~m}$ shuttle run test of Colombian adolescents classified by age and sex, expressed regarding the $\mathrm{Z}$ score values. In these, a better muscular and cardiorespiratory performance by male students can be seen in each of the three tests evaluated. Overall, there is greater heterogeneity in the values of the males compared to the values of the females, which are more homogeneous. Likewise, in the males, there is a tendency towards an increase in the level of physical fitness as age increases, in contrast to the females, who show a tendency towards stability.

\section{Discussion}

Analyzing the descriptive results of this study, we found that the BMI values and fat percentage concurred with the studies carried by Palomino (Palomino-Devia et al., 2017) and Dantas (Dantas et al., 2013) in which males and females aged 12 to 17 years were compared and in which greater adiposity was found in female adolescents.

In a study carried on 697 students aged 12 to 19 years in Rio de Janeiro, the BMI of both males and females was higher compared to the data in the present study, while fat percentage and waist circumference were lower in both males and females (Schultz Straatmann \& Veiga, 2015). In the same way, BMI was similar in a study that evaluated 195 adolescents aged 14 to 18 years (Dowd et al., 2016).

However, if we analyze the variables related to physical fitness, as in the present study, different studies (Black et al., 2016; Grao-Cruces et al., 2015; Palomino-Devia et al., 2017; Silva et al., 2012) have found differences between the sexes, showing better results in the male gender in comparison to the female gender in the long jump test, the $20 \mathrm{~m}$ shuttle run test and the manual grip.

This study also reveals, for the first time in Colombia, the normalized percentiles of muscular and cardiorespiratory performance by age and sex; values that can be used as a reference in the assessment of physical fitness concerning the nutritional status and body composition in the school population. In summary, and as established by different authors (Pacheco et al., 2016; Patiño Palma et al., 2019; Secchi et al., 2016), in the studied population, higher values of muscular and cardiorespiratory fitness were observed in the male school children evaluated, highlighting the significant increase as age increases, a difference explained mainly by the different factors of biological maturation.

The joint analysis of muscle strength in a single index as explained in our methodology coincides with the methodological strategies reported in previous studies on children and adolescents (Artero et al., 2011; GarcíaArtero et al., 2007; Pacheco et al., 2016) as well as with European population-based studies such as AVENA (Francisco Ortega et al., 2005), HELENA (F. Ortega et al., 2011), and ALPHA (J. Ruiz et al., 2011).

Due to the lack of normative values for the Colombian population, the data reported in this work facilitate comparison with international reference values (established in the studies mentioned above), however, it is essential to explain the correct interpretation of these data; in this sense, to facilitate the classification, reference values from reported data are presented in Tables 3 and 4, allowing an intuitive classification of the components assessed from a Likert-type scale as follows: Very bad (X d» -3SD ), Bad (-3SD d» X d» -2SD), Fair $(-2 S D d » X d »-1 S D)$, Normal (-1SD d» $X \mathrm{~d} » 1 S D)$, Good (1SD d» $\mathrm{X} d$ » 2SD), Very good (2SD d» $\mathrm{X} d$ » 3SD), and excellent (X e» 3SD).

Another finding in this study was the inverse relationship between the cardiorespiratory and muscular fitness and body dimension measurements in the general adolescent population, a result that is consistent with that reported by Rodríguez (Rodríguez et al., 2015). These authors found that children and adolescents in Bogota city, Colombia, with lower muscular performance had approximately 4 times the risk of having high body fat levels and 1.57 times the risk of abdominal obesity. In this sense, and based on these observations, we found concordance with the hypothesis of the protective role of fat-free mass in the risk of presenting cardiovascular diseases (Pacheco et al., 2016; Patiño Palma, 2019; Schultz Straatmann \& Veiga, 2015). For example, in young Colombians, Correa (CorreaRodríguez et al., 2018) showed that better muscle performance was inversely associated with a healthier metabolic profile. This leads us to assume that the muscle component can be considered an indicator of cardiovascular health with high discriminatory power, a conclusion that is consistent with the mentioned by Eckman (Eckman et al., 2016) and Fonseca (FonsecaCamacho et al., 2015).

The above shows how body composition influences the assessment of muscle strength, therefore, it must be taken into account when assessing strength in adolescents (McGrath et al., 2019); However, authors 
such as Dongxue Li et al (Li et al., 2018) establish that a greater relative grip strength is associated with a more favorable metabolic profile, thus a lower risk of metabolic disease. Therefore, the measurement of relative grip strength is a greater predictor of metabolic disease than the absolute measurement of grip strength, a situation that agrees with the correlation indices shown in this study.

The physical fitness test used was selected based on scientific evidence from previous studies, $20 \mathrm{~m}$ Shuttle Run Test, handgrip strength, and the long jump test have been proved to be valid, reliable, and feasible for health monitoring on the adolescent population (J. Ruiz et al., 2011). Handgrip strength and long jump test have shown good validity compared to laboratory-based strength tests for both upper and lower body, suggesting the use of these as suitable measures of muscular fitness, however, the inclusion of other dimensions of muscular fitness, e.g., muscular endurance, and isokinetic strength, should be considered in future studies.

The observations of the present study are limited by the nature of the cross-sectional design, limiting the ability to determine causality in the relationship of the study variables; Likewise, other variables that may influence body composition or GSI were not taken into account, such as diet, ethnicity, socioeconomic level, state of biological maturation, nutritional status and level of physical activity of the schoolchildren. In addition to the above, endocrine factors or other physical fitness markers such as anaerobic power were not evaluated or taken into account. Prospective and interventional studies are needed to draw more solid conclusions.

\section{Conclusion}

These results provide nationally valid standards for cardiovascular and muscular fitness in Colombian adolescents, offering new perspectives on the health and nutritional status of this population, which can be taken into account by institutional actors involved in the planning, decision making, and implementation of health policies in the country. In general, the assessment of muscular fitness and cardiorespiratory fitness can be considered as a complementary assessment tool that can be included in academic programs aimed at primary prevention in schools.

\section{Acknowledgments}

The authors would like to thank the students of the third cohort of the master's degree in Physical Activity and Sport of Universidad Autónoma de Manizales for their technical and logistical support in the field measurements.

Finally, special thanks are sent to all the school children who participated in this study, without whom this would not have been possible.

\section{Author Contributions}

BEPP carried out the data cleaning, tabulation, and statistical analysis. He also wrote the first draft of the study. PACS and CARP carried out the study design and systematization of the data.

All authors reviewed and approved the final version of the manuscript sent to the editor.

\section{Conflict of interest}

The authors declare that they have no conflict of interest.

\section{Reference}

Álvarez Caro, F., Díaz Martín, J. J., Riaño Galán, I., Pérez Solís, D., Venta Obaya, R., \& Málaga Guerrero, S. (2011). Factores de riesgo cardiovascular clásicos y emergentes en escolares asturianos. Anales de Pediatria, 74(6), 388-395. https://doi.org/ 10.1016/j.anpedi.2011.01.007

Artero, E. G., Ruiz,J. R., Ortega, F. B., España-Romero,V.,Vicente-Rodríguez, G., Molnar, D., Gottrand, F., González-Gross, M., Breidenassel, C., Moreno, L.A., \& Gutiérrez,A. (2011). Muscular and cardiorespiratory fitness are independently associated with metabolic risk in adolescents: The HELENA study. Pediatric Diabetes, 12(8), 704-712. https://doi.org/ 10.1111/j.1399-5448.2011.00769.x

Black, N. E.,Vehrs, P.R., Fellingham, G.W., George,J. D., \& Hager, R. (2016). Prediction ofVO2max in Children andAdolescents Using Exercise Testing and Physical Activity Questionnaire Data. Research Quarterly for Exercise and Sport, 87(1), 89-100. https://doi.org/10.1080/02701367.2015.1124969

Carvajal, M., Castro, P., Dueñas, F., Martinez, J., Suarez, J., \& Velásquez, G. (2012). Riesgo cardiovascular en estudiantes universitarios. Rev.Salud.Hist.Sanid.on-Line, 7(2), 23-35.

Cole, T. J., \& Green, P. J. (1992). Smoothing reference centile curves: The lms method and penalized likelihood. Statistics in Medicine, 11(10), 1305-1319. https://doi.org/10.1002/ sim.4780111005

Correa-Rodríguez, M., Ramírez-Vélez, R., Correa-Bautista, J.E., Castellanos-Vega, R. del P.,Arias-Coronel, F., González-Ruíz, K., Carrillo,H.A., Schmidt-Riovalle, J., \& González-Jiménez, E. (2018). Association of muscular fitness and body fatness with cardiometabolic risk factors: The FUPRECOL study. 
Nutrients, 10(11). https://doi.org/10.3390/nu10111742

Dantas, M.,Alencar de Oliveira, P.,Alves da Silva,T., Oliveira, F., \& Schwingel, P. (2013). Association between indicators of corporal adiposity and cardiovascular risk factors among Brazilian adolescents. Journal of Exercise Physiology Online, 16(6), 69-78.

Dowd, K., Harrington, D., Hannigan, A., Purtill, H., Kelly, S. M., Macken,A. P., Moyna, N., O' Gorman, C. S., \& Donnelly,A.E. (2016). The development of activity profiles in adolescent females and their association with adiposity. Pediatric Exercise Science, 28(1), 109-116. https://doi.org/10.1123/ pes.2015-0081

Eckman, M., Gigliotti, C., Sutermaster, S., Butler, P.J., \& Mehta, K. (2016). Using handgrip strength to screen for diabetes in developing countries. Journal of Medical Engineering andTechnology, 40(1), 8-14. https://doi.org/10.3109/ 03091902.2015.1112855

El-gohary,T. M.,AbdElkader, S. M.,Al-shenqiti,A.M., \& Ibrahim, M. I. (2019).Assessment of hand-grip and key-pinch strength at three arm positions among healthy college students: Dominant versus non-dominanthand. Journal ofTaibah University Medical Sciences, 14(6), 566-571. https://doi.org/10.1016/ j.jtumed.2019.10.001

Fonseca-Camacho, D. F., Hernández-Fonseca, J. M., GonzálezRuíz, K., Tordecilla-Sanders,A., \& Ramírez-Vélez, R. (2015). Una mejor auto-percepción de la condición física se relaciona con menor frecuencia y componentes de síndrome metabólico en estudiantes universitarios. Nutricion Hospitalaria, 31(3), 1254-1263. https://doi.org/10.3305/ nh.2015.31.3.8398

García-Artero, E., Ortega, F. B., Ruiz, J. R., Mesa, J. L., Delgado, M., González-Gross, M., García-Fuentes, M., VicenteRodríguez, G., Gutiérrez, Á., \& Castillo, M. J. (2007). Lipid and metabolic profiles in adolescents are affected more by physical fitness than physical activity (AVENA study). Revista Espanola de Cardiologia, 60(6), 581-588. https://doi.org/ 10.1157/13107114

Gómez-Campos, R., Vásquez, F. A., Pezoa-Fuentes, P., RiveraPortugal, M., Luarte-Rocha, C., Urra-Albornoz, C., \& CossioBolaños, M. (2020). Pruebas de aptitud física que realizan los escolares. Salud(i)Ciencia, 23(8), 626-631. https://doi.org/ $10.21840 / \mathrm{siic} / 161156$

Grao-Cruces, A., Nuviala, A., \& Fernández-Martínez,A. (2015). Valoración del programa Escuelas Deportivas: Composición corporal, actividad física y capacidad aeróbica en adolescentes (Assessment of the Sport Schools program: Body composition, physical activity and cardiorespiratory fitness in adolescents). Retos, 27(27), 105-108. https://doi.org/10.47197/ retos.v0i27.34357

Janssen,A., Leahy,A.A., Diallo,T.M. O., Smith,J.J., Kennedy, S. G., Eather, N., Mavilidi, M. F., Wagemakers, A., Babic, M. J., \& Lubans, D. R. (2020). Cardiorespiratory fitness, muscularfitness and mental health in older adolescents: A multi-level crosssectional analysis. Preventive Medicine, 132. https://doi.org/ 10.1016/j.ypmed.2020.105985

Kara, Ö., Kara, M., Ak1n, M. E., \& Özçakar, L. (2021). Grip strength as a predictor of disease severity in hospitalized COVID-19 patients. Heart \& Lung, 50(6), 743-747. https: / / doi.org/10.1016/j.hrtlng.2021.06.005

Kidokoro,T., Kohmura,Y., Fuku, N., Someya,Y., \& Suzuki, K. (2020). Secular trends in the grip strength and body mass index of sport university students between 1973 and 2016: J-Fitÿstudy. Journal of Exercise Science and Fitness, 18(1), 21-30. https:// doi.org/10.1016/j.jesf.2019.08.002

Kim,Y.M.,Kim,S., Bae,J.,Kim, S.H.,\&Won,Y.J.(2021).Association between relative hand-grip strength and chronic cardiometabolic and musculoskeletal diseases in Koreans: A cross-sectional study. Archives of Gerontology and Geriatrics, 92. https:/ / doi.org/10.1016/j.archger.2020.104181

Kodama, S., Saito, K., Tanaka, S., Maki, M., Yachi,Y., Asumi, M., Sugawara,A., Totsuka, K., Shimano, H., Ohashi,Y.,Yamada, N., \& Sone, H. (2009). Cardiorespiratory fitness as a quantitative predictor of all-cause mortality and cardiovascular events in healthy men and women: A meta-analysis. In JAMA - Journal of the American Medical Association (Vol. 301, Issue 19, pp. 2024 2035). JAMA. https://doi.org/10.1001/jama.2009.681

Leong, D. P., Teo, K. K., Rangarajan, S., Lopez-Jaramillo, P.,Avezum, A., Orlandini, A., Seron, P., Ahmed, S. H., Rosengren, A., Kelishadi, R., Rahman, O., Swaminathan, S., Iqbal, R., Gupta, R., Lear, S.A., Oguz, A.,Yusoff, K., Zatonska, K., Chifamba, J., ... Yusuf, S. (2015). Prognostic value of grip strength: Findings from the Prospective Urban Rural Epidemiology (PURE) study. The Lancet, 386(9990), 266-273. https://doi.org/ 10.1016/S0140-6736(14)62000-6

Li,D., Guo, G., Xia, L.,Yang, X., Zhang, B., Liu, F., Ma, J., Hu, Z., Li, Y., Li, W., Jiang, J., Gaisano, H., Shan, G., \& He, Y. (2018). Relative handgrip strength is inversely associated withmetabolic profile and metabolic disease in the general population in China. Frontiers in Physiology, 9(FEB), 59. https://doi.org/ 10.3389/fphys.2018.00059

Lima-Serrano, M., Martínez-Montilla, J. M., Guerra-Martín, M. D. Vargas-Martínez, A. M., \& Lima-Rodríguez, J. S. (2018). Factores relacionados con la calidad de vida en la adolescencia. Gaceta Sanitaria, 32(1), 68-71. https://doi.org/10.1016/ j.gaceta.2016.06.016

Magee, M. K., White, J. B., Merrigan, J. J., \& Jones, M.T. (2021). Does the multistage 20-m shuttle run test accurately predict vo2max in NCAA division I women collegiate field hockey athletes? Sports, 9(6). https://doi.org/10.3390/ sports 9060075

Matsuzaka,A.,Takahashi,Y.,Yamazoe, M., Kumakura, N., Ikeda,A., Wilk, B., \& Bar-Or, O. (2004).Validity of the multistage 20-m shuttle-run test for Japanese children, adolescents, and adults. Pediatric Exercise Science, 16(2), 113-125. https://doi.org/ 10.1123/pes.16.2.113

Mayorga,D.,Viciana, J., \& Cocca,A.(2012). Relationship between Physical Self-Concept and Health-Related Physical Fitness in Spanish Schoolchildren. Procedia - Social and Behavioral Sciences, 69, 659-668. https://doi.org/10.1016/ j.sbspro.2012.11.458

McGrath, R., Hackney, K. J., Ratamess, N. A., Vincent, B. M., 
Clark, B. C., \& Kraemer,W.J. (2019).Absolute and Body Mass Index Normalized Handgrip Strength Percentiles by Gender, Ethnicity, and Hand Dominance in Americans. Advances in Geriatric Medicine and Research, 2(1). https://doi.org/ 10.20900/agmr20200005

Ortega, F., Artero, E., Ruiz, J. R., Espana,V., Jimenez,D.,Vicente, G., Moreno,L., Manios,Y., Beghin, L., Ottevaere, C., Ciarapica, D., Sarri, K., Dietrich, S., Blair, S. N., Kersting, M., Molnar, D., Gonzalez-Gross, M., Gutierrez,A., Sjostrom, M., \& Castillo, M. (2011). Physical fitness levels among European adolescents: the HELENA study. British Journal of Sports Medicine, 45(1), 20-29. https://doi.org/10.1136/ bjsm.2009.062679

Ortega, F. B., Silventoinen, K., Tynelius, P., \& Rasmussen, F. (2012). Muscular strength in male adolescents and premature death: Cohort study of one million participants. BMJ (Online), 345(7884). https://doi.org/10.1136/bmj.e7279

Ortega, Francisco, Ruiz, J., Castillo, M., Moreno, L., González, M.,Wärnberg,J., \& Gutiérrez,A. (2005).Low level of physical fitness in Spanish adolescents. Relevance for future cardiovascular health (AVENA study). Revista Espanola de Cardiologia, 58(8), 898-909. https://doi.org/10.1016/ S1885-5857(06)60372-1

Ortega, Francisco, Silventoinen, K., Tynelius, P., \& Rasmussen, F. (2012). Muscular strength in male adolescents and premature death: Cohort study of one million participants. BMJ (Online), 345(7884). https://doi.org/10.1136/bmj.e7279

Pacheco, J., Ramírez, R., \& Enrique, J. (2016). Índice general de fuerza y adiposidad como medida de la condición física relacionada con la salud en niños y adolescentes de Bogotá, Colombia: Estudio FUPRECOL. Nutrición Hospitalaria, 33(3), 556-564. https://doi.org/10.20960/nh.261

Palomino-Devia, C., González-Jurado, J.A., \& Ramos-Parraci, C. A. (2017). Body composition and physical fitness in Colombian high school students from Ibagué. Biomedica/ : Revista Del Instituto Nacional de Salud, 37(3), 408-415. https: / / doi.org/ 10.7705/biomedica.v37i3.3455

Patiño Palma, B. E. (2019). Factores asociados a la condición física relacionada con la salud en escolares de la ciudad de Dosquebradas Risaralda. Revista Investigación En Salud Universidad de Boyacá, 6(2), 118-136. https: / /doi.org/10.24267/ 23897325.343

Patiño Palma, B. E., Tabares Gutierrez, M., Vélez Álvarez, C., \& Vidarte Claros, J. A. (2019). Determinantes sociales de la salud, predictores de la condición física en adolescentes escolares. Revista Investigaciones Andina, 21(39), 117-131. https: / / doi.org/10.33132/01248146.1559

Rodríguez, F., Gualteros, J., Torres, J., Espinosa, L. M., \& Ramírez, R. (2015). Asociación entre el desempeño muscular y el bienestar físico en niños y adolescentes de Bogotá, Colombia. Nutricion Hospitalaria, 32(4), 1559-1566. https://doi.org/ 10.3305/nh.2015.32.4.9310

Ruiz, J., España, V., Castro, J., Artero, E., Ortega, F., García, M., Chillón, P., Girela, M., Mora, J., Suni, J., Sjöstrom, M., \& Castillo, M. (2011). BateríaALPHA-Fitness/ : test de campo para la evaluación de la condición física relacionada con la salud en niños y adolescentes. Nutrición Hospitalaria, 26(6), 1210 1215. https://doi.org/10.3305/nh.2011.26.6.5270

Ruiz,J.R., Castro-Piñero, J.,Artero, E. G., Ortega, F. B., Sjöström, M., Suni, J., \& Castillo, M. J. (2009). Predictive validity of health-related fitness in youth: A systematic review. In British Journal of Sports Medicine (Vol. 43, Issue 12, pp. 909-923). Br J Sports Med. https://doi.org/10.1136/bjsm.2008.056499 Schultz Straatmann, V., \&Veiga, G.V.Da. (2015). Cardiorespiratory Fitness, Physical Activity, and Indicators of Adiposity in Brazilian Adolescents. Human Movement, 16(2), 64-70. https:// doi.org/10.1515/humo-2015-0028

Secchi, J., García, G., \& Arcuri, C. (2016). Evaluación de la condición física relacionada con la salud en el ámbito escolar: un enfoque práctico para interpretar e informar los resultados. Enfoques, 28(2), 67-87.

Silva, G., Oliveira, N. L., Aires, L., Mota, J., Oliveira, J., \& Ribeiro, J. C. (2012). Calculation and validation of models for estimating VO 2 max from the 20-m shuttle run test in children and adolescents. Archives of Exercise in Health and Disease, 3(1-2), 145-152. https://doi.org/10.5628/aehd.v3i1-2.20

Silventoinen, K., Magnusson, P. K. E., Tynelius, P., Batty, G. D., \& Rasmussen, F. (2009). Association of body size and muscle strength with incidence of coronary heart disease and cerebrovascular diseases: A population-based cohort study of one million Swedish men. International Journal of Epidemiology, 38(1), 110-118. https://doi.org/10.1093/ije/dyn231

Slaughter, M. H., Lohman, T. G., Boileau, R. A., Horswill, C.A., Stillman, R. J., Van Loan, M. D., \& Bemben, D. A. (1988). Skinfold equations for estimations of body fatness in children and youth. Human Biology, 60(5), 709-723.

Stasinopoulos, D. M., \& Rigby, R. A. (2007). Generalized additive models for location scale and shape (GAMLSS) in R. Journal of Statistical Software, 23(7), 1-46. https://doi.org/10.18637/ jss.v023.i07

Syddall, H., Cooper, C., Martin, F., Briggs, R., \& Sayer,A.A. (2003). Is grip strength a useful single marker of frailty? Age and Ageing, 32(6), 650-656. https://doi.org/10.1093/ageing/afg111

Wilson, A., \& Norden, N. (2015). The R Project for Statistical Computing The R Project for Statistical Computing. URL: Http: / / Www. r-Project. Org/254. https://www.r-project.org/

World Health Organization (WHO). (1995). Physical Status: the use and interpretation of anthropometry. Report of aWHO expert committee. In Journal of Geriatric Oncology (Vol. 1, Issue 1, pp. 1-436).

Zaccagni, L., Barbieri, D., \& Gualdi-Russo, E. (2014). Body composition and physical activity in Italian university students. Journal of Translational Medicine, 12(1). https://doi.org/ 10.1186/1479-5876-12-120

Zorrilla-López, C., Ceballos-Santacruz,J.D., Ramírez-Giraldo, C. D., Patiño-Palma, B. E., \& Calero-Saa, P. (2020). Factors associated with cardiovascular risk in high school students of a public school in the city of Santiago de Cali, Colombia. Revista Ciencias de La Salud, 18(1), 24-36. https://doi.org/ 10.12804/revistas.urosario.edu.co/revsalud/a.8741 